\title{
La enfermedad crónica: el reflejo de una imagen
}

\author{
Lidia Moscoso Naya \\ Enfermera del Hospital Comarcal Valdeorras. O Barco de Valdeorras (Orense)
}

¿Cómo vive el paciente crónico su enfermedad?, ¿de qué forma interfiere en su vida personal, social o laboral?, ¿qué espera del mundo sanitario y de los profesionales a los que confía su salud? Y ¿cuál debería ser la actitud de éstos respecto al paciente?

Soy enfermera y padezco una enfermedad de Crohn. Por esta condición de enferma crónica y enfermera asistencial quisiera aportar mi experiencia desde esta doble óptica.

Cuando observo la obra de Frida Khalo me siento identificada. En sus cuadros pintaba el reflejo de su imagen en el espejo, en donde observaba una imagen de si misma sin el dolor físico que sentía.

Afrontar una enfermedad crónica no sólo es aprender a vivir con los síntomas y los efectos adversos de los tratamientos, implica enfrentarse a limitaciones en todos los aspectos de la vida. Te encuentras ante una situación donde tu rutina se ve reemplazada por incertidumbre.

La cronicidad de una enfermedad presenta desafíos muy distintos a una enfermedad aguda, que sabes que tendrá un final. Pero ¿qué ocurre cuando los síntomas no desaparecen nunca? ¿Cómo enfrentarnos a esto?

Enfrentarse al diagnóstico conlleva un proceso de duelo, donde se produce una lucha interna entre tus deseos y la realidad que te viene impuesta; supone tener que admitir que muchos aspectos de tu vida no volverán a ser los mismos. Sentimientos que vuelves a revivir en los momentos de exacerbación de la enfermedad, llevándote a un agotamiento psicológico que repercute en tu vida y en la de los que te rodean.

Por ello es importante encontrar un equilibrio entre la enfermedad y sus repercusiones. Equilibrio, que se ve amenazado cuando los síntomas están presentes día tras día. Porque ¿cómo mantener el optimismo y la vitalidad cuando padeces una astenia severa o cuando el dolor es invalidante y no cede con ningún analgésico? Para no romper este equilibrio, recurres al silencio. Pero no hablar de ello, no significa que no siga sucediendo, pasa a ser un sufrimiento latente que no es visible para los demás.

Esta sensación de soledad e incomprensión se extiende a las relaciones sociales y laborales, donde en ocasiones puedes sentirte víctima del rechazo. El dolor, la fatiga y otros muchos síntomas, presentes en el día a día, interfieren en una vida social fluida y en el desempeño de tu trabajo. Las relaciones con tus compañeros pueden verse amenazadas debido a la sobrecarga de trabajo que tus limitaciones, ausencias 0 bajas pueden ocasionar.

Cuando la enfermedad empeora y es necesario el ingreso, descubres que la hospitalización es también un motivo de miedo, vulnerabilidad, rabia. Sientes que tu vida se detiene, sintiéndote encarcelado en tu propia enfermedad. Necesitas ayuda, lo que genera frustración, al perder tu autonomía. De ahí que los sanitarios jueguen un papel crucial; el enfermo espera comprensión ante la situación que vive. Lamentablemente no siempre es así. También entre los profesionales hay desconocimiento y rechazo, incluso insensibilidad ante la "persona" que tienen delante.

Todos conocemos el concepto de cuidados integrales pero, ¿realmente creemos de lo qué hablamos? ¿estamos dispuestos como sanitarios a llevar a la práctica lo que fácilmente exponemos en un papel o en una charla? ¿hasta qué punto estamos comprometidos a realizarlo en nuestro día a día? No deberíamos excusarnos en la carga de trabajo 0 la falta de tiempo, porque aunque sin duda esto sea una realidad, empatizar con el paciente requiere cero minutos $y$, si de tiempo se trata, por qué perderlo prejuzgando.

Cuando estamos ante un paciente que vemos por primera vez 0 en contadas ocasiones, nos creemos con derecho a juzgar sus reacciones cuando tan sólo conocemos un breve resumen de su historia clínica, donde probablemente nos hemos centrado en los datos clínicos. Pero, ¿qué o cuánto conocemos de nuestro paciente? ¿Conocemos los factores externos que indudablemente repercuten en su estado de salud? ¿Conocemos qué tipo de trabajo desempeña o qué carga de estrés y responsabilidades tiene en su vida?, ¿conocemos la forma en que se enfrenta a la enfermedad 0 a los efectos secundarios de los tratamientos?, ¿los apoyos que tiene 0 de los que carece?...

No prestar atención a todas estas cuestiones 0 al impacto de la enfermedad en la vida del paciente es un error. Su bienestar está interrelacionado con el estrés y éste a su 


\section{"Afrontar una enfermedad crónica no sólo es aprender a vivir con los síntomas y los efectos adversos de los tratamientos, implica enfrentarse a limitaciones en todos los aspectos de la vida."}

vez con el sistema neuro-endocrino e inmunológico, donde incluso cantidades moderadas de estrés puede intensificar los síntomas; debemos, por tanto, tener presente su estado emocional. Pero jojo! No confundamos dicho agravamiento de los síntomas con la somatización, este empeoramiento es la consecuencia real de la repercusión emocional de la enfermedad.

Otro error en el que caemos como profesionales es no escuchar las sugerencias del enfermo. Cuando te encuentras ante un paciente que ha vivido muchas hospitalizaciones a lo largo de su vida y que por lo tanto es conocedor de sus tratamientos, solemos llamarle "rata de hospital", expresión enormemente peyorativa que pone en entredicho no sólo nuestra ética profesional sino también nuestra ética como personas. No olvidemos que el paciente lleva años padeciendo y conviviendo con la enfermedad y sus tratamientos y quizá haya tenido malas experiencias en anteriores ingresos. Por tanto, debemos escucharle y aceptar sus opiniones, no sentirnos amenazados ni ponernos a la defensiva. Trabajar conjuntamente con él es positivo para el enfermo y para el resultado final de sus cuidados.

Recuerdo que cuando empezaron los primeros síntomas de mi enfermedad tenía 17 años, no era capaz de digerir la comida, vomitaba y comer era sinónimo de dolor. Esto, junto a ser una adolescente llevó a un diagnóstico erróneo: Anorexia nerviosa. Cualquier síntoma que no encajara con dicho diagnóstico era tan sólo la somatización de una adolescente que quería llamar la atención. Existía un diagnóstico y aunque fuese un diagnóstico erróneo, era un diagnóstico. Así que ningún profesional que me vio durante aquellos años se lo cuestionó. Esto duró cerca de seis años, seis largos años en los cuales la enfermedad evolucionó a sus anchas. Cuando aparecieron los primeros síntomas extradigestivos, una artritis invalidante llevó a un reumatólogo al diagnostico de la enfermedad de Crohn. Ante aquello, ¿cómo tenía que sentirme?, ¿alegre porque volvieran a creer en mi 0 indignada porque nadie me hubiese escuchado durante aquellos seis años?

No sólo no se trató la enfermedad, no se trataron ni tan siquiera los síntomas. ¿Para qué paliar algo que era producto de mi imaginación? ¿dolor? No existía, tan sólo era una manera de llamar la atención. No fui yo quien somaticé los síntomas, sino aquellos que me rodearon: médicos, amigos e incluso familiares.

Sin embargo, a pesar de recuperar la credibilidad de aquellos años, esto no perduró en el tiempo, pese a tener un diagnóstico real. Existen otras muchas facetas a lo largo de la vida del enfermo que se ponen en entredicho. Lo que no se ve no existe.

Cuando tuve la obstrucción intestinal, en las pruebas de imagen sólo se veían $20 \mathrm{~cm}$ de estenosis. Se preparó una cirugía por laparoscopia. A mi y a mi familia nos dijeron que la intervención duraría unas 2 horas. Estuve en quirófano 6 ! En el postoperatorio me explicaron que tuvieron que extirparme $90 \mathrm{~cm}$ de intestino y realizar 3 dilataciones plásticas para evitar una mayor resección. Pero... en el SCANER se veían únicamente $20 \mathrm{~cm}$ de estenosis.

No sólo en mi experiencia personal como enferma sino también a lo largo de mi vida profesional he podido constatar que las pruebas de imagen, por muy sofisticadas que sean, sólo son pruebas complementarias que ayudan a ir hacia un diagnóstico. Pero la clave siempre está en la clínica y esa clínica, esos síntomas, son los que aporta el paciente. Debemos no sólo escucharles, debemos creerles.

Necesitamos como enfermos que la sociedad nos escuche y que entiendan nuestra limitaciones. Necesitamos como enfermos que nos ayuden a superar trabas que de otro modo no podríamos superar. Por tanto, como sanitarios debemos dejar a un lado nuestro orgullo profesional y hacerle partícipe de sus cuidados.

Adoptar un papel activo como enfermos, nos permite sentirnos más fuertes y preparados para aprender a convivir con los síntomas y superar las trabas que nos deparara la evolución de la enfermedad. No será fácil pero debemos intentarlo. La lucha es continua y las batallas se han de librar día a día, pero, con la comprensión y el apoyo de nuestra pareja, familia y amigos y, con el correcto saber hacer de los profesionales implicados, se puede conseguir. 